\title{
Vaardigheidsonderwijs nu en in de toekomst
}

\author{
A.J.J.A. Scherpbier, G.M. Verwijnen, N. Schaper, G.A.J. Dunselman, C.P.M. van der Vleuten
}

\section{Samenvatting}

Vaardgheidsonderwis wordt in alle opleidingen voor de gezondheidstorg gegeven in dit artikel word het vaardigheidsonderwis in Mastricht beschreven. Uit onderzoek nat de effecten van dit onderwij blikt dat het vaddge studenten oplevert De vrag die we ons, als docenten, moeten stellen, is of het niet nog beter kan. De beanwoording van deze vraag leid tot een toekoms tbeld voor het (vaardigheids jonderwis. Een belangrike conchise is dat de patient een centrale plaats moet krigen. De patent is als het ware de rode draad door het curriculum.

\section{Summary}

All health care education programmes include skills training. This article describes the shiIns traing courses of the Mastricht Medical school undergraduate curriculum. Studis have provided evidence that this programme yields shillful students. As teachers we should always be asking ourselves if we can do better stil. In answering this question we picture the future of (skills) training. One of the main conclusions is that future training courses must be patient centred. The patent is to become the basic thread runing through the ourriculum from beginning to end. (Scherpbier AJA, Verwinen GM, Schoper $N$, Dunselman GAJ, van der Vleuten CPM. Current and future skils training. Dutch Journal of Medical Education 2000; $19(1) 6-15)$

\section{Inleiding}

Vaardigheidsonderwijs heeft in het gezondheidszorgonderwijs de afgelopen twintig jaar een duidelijke plaats gekregen. Het is inmiddels "gewoon" dat studenten zich in hun opleiding, naast kennis, ook vaardigheden eigen maken. In het gezondheidszorgonderwijs is vaardigheidsonderwijs van belang als voorbereiding op patiëntencontacten. De vraag is of deze voorbereiding beter kan. In dit artikel wordt het vaardigheidsonderwijs beschreven zoals dat in Maastricht ontwikkeld is, en worden uitkomsten van onderzoek naar de effecten van dit onderwijs besproken. Vervolgens wordt een toekomstbeeld voor het medisch onderwijs geschetst op basis van inzichten over leren uit de cognitieve psychologie. Tenslotte wordt beschreven wat de conse- quenties daarvan zijn voor het vaardigheidsonderwijs.

\section{Vaardigheidsonderwijs in het Skillslab}

In het onderstaande worden historie, opbouw en inhoud van het Maastrichtse vaardigheidsonderwijs beschreven. Ook wordt ingegaan op de toetsing en hoe het in de praktijk gaat. Voor lezers die meer willen weten, wordt verwezen naar andere publicaties. 12

\section{Historie}

Bij de oprichting van de faculteit geneeskunde in Maastricht is gekozen voor een probleemgeoriënteerd onderwijssysteem. Een studiejaar bestaat uit thematische blokken, die door multidisciplinair samengestelde blokplanningsgroepen worden ontwikkeld en uitgevoerd. Aanvankelijk 
waren vaardigheidstrainingen gepland in het vierde blok van het eerste jaar. De trainingen werden ten dele georganiseerd in de doktersassistentenschool in Heerlen. De studenten vonden echter dat het vaardigheidsonderwijs al vanaf het begin van het eerste jaar en alleen in Maastricht gegeven moest worden. ${ }^{1}$ In 1975 , een jaar na de start van het curriculum, werd besloten om een Skillslab op te richten. Dit Skillslab werd toen gezien als een faciliteit, waar studenten docent-onafhankelijk vaardigheden konden oefenen op de momenten dat zij daar aan toe waren. In de praktijk bleek dat studenten vaak begeleiding van een docent vroegen. Doordat docenten niet beschikbaar waren op momenten dat studenten wilden oefenen en door het groeiend aantal studenten was binnen een paar jaar duidelijk dat het concept van de docent-onafhankelijke faciliteit in de praktijk niet uitvoerbaar was. Er werden docenten voor het vaardigheidsonderwijs aangesteld en er werd een curriculum voor het vaardigheidsonderwijs ontwikkeld. Er ontstond een Skillslab als zelfstandige beheerseenheid binnen de Faculteit der Geneeskunde.

\section{De opbouw van het curriculum}

In Maastricht wordt het vaardigheidsonderwijs verspreid over de eerste vier jaar van de studie gegeven. In veel andere faculteiten heeft het vaardigheidsonderwijs nog de vorm van een korte cursus. Het streven is om de vaardigheidstrainingen zo goed mogelijk aan te laten sluiten bij de onderwerpen die in het theoretisch curriculum aan bod komen en bij de patiënten- en praktijkcontacten in de eerste vier studiejaren (horizontale integratie). Omdat ook verticale integratie van belang is, worden eerst de basisprincipes van een onderzoek aangeleerd en wordt het onderzoek later in het curriculum geoefend op basis van een casus of bij een (simulatie)patiënt. Ook zijn er zorgvuldig geplande herhalingen. Inhoud en opbouw van het vaardigheidsonderwijs in de eerste vier studiejaren moeten zodanig zijn dat de studenten goed voorbereid worden op de co-assistentschappen. Een andere belangrijke factor bij de invulling van het curriculum is een gelijkmatige spreiding van de hoeveelheid onderwijs over het studiejaar, zowel voor studenten als docenten. Bij de afwegingen tussen deze verschillende "belangen" moeten (verstandige) compromissen gesloten worden.

\section{De inhoud van het vaardigheidsonderwijs}

Studenten leren en oefenen vaardigheden in trainingen, gegeven in het Skillslab door Skillslabdocenten en/of georganiseerd door het Skillslab. Deze vaardigheden zijn onder te verdelen in vier categorieën.

- Laboratoriumvaardigheden: eenvoudige diagnostische technieken, zoals bijvoorbeeld een huisarts ze zou kunnen toepassen. Ook wordt aandacht besteed aan indicatiestelling en interpretatie van begrippen als specificiteit en sensitiviteit van testen.

- Therapeutische vaardigheden: verschillende injecteertechnieken, het aanleggen van verbanden, het hechten van een wond, resuscitatietechnieken, et cetera.

- Fysisch diagnostische vaardigheden: de vaardigheden die de arts gebruikt bij het lichamelijk onderzoek.

- Communicatievaardigheden: de vaardigheden die de arts nodig heeft om een gesprek goed te laten verlopen en om gegevens te verzamelen via anamnese en onderzoek.

Deze vaardigheden oefenen studenten in het begin op elkaar en later op (simulatie)patiënten. De einddoelen die na vier jaar bereikt moeten worden, zijn in overleg met klinische docenten vastgesteld. ${ }^{3}$ 


\section{Toetsing}

De kennis over de vaardigheden die in een blok aan de orde zijn geweest, wordt getoetst in de schriftelijke bloktoetsen aan het eind van ieder blok. In de voortgangstoets wordt de "overall" kennis over vaardigheden op basisartsniveau getoetst. 4 De beheersing van vaardigheden wordt elk jaar beoordeeld in een stationsexamen, waarvoor de studenten moeten slagen. De inhoud van het stationsexamen is cumulatief.5, 6 Aan het einde van het eerste jaar worden de vaardigheden uit het eerste jaar getoetst, aan het einde van het tweede jaar de vaardigheden uit het eerste en tweede jaar, et cetera.

\section{Hoe gaat het in de praktijk?}

Het inschrijven voor trainingen is niet verplicht, omdat het besluit om wel of niet een training te volgen gezien wordt als de verantwoordelijkheid van de stu- dent zelf. Wel betekent inschrijving dat er van de studenten verwacht wordt dat ze de betreffende training volgen. De opkomst bij de trainingen is hoog (figuur 1).7, 8

Enkele weken voor elk blok wordt nagegaan wanneer de docenten beschikbaar zijn. Voor elke training worden voor elke jaargroep voldoende mogelijkheden ingepland, waarbij rekening gehouden wordt met andere onderwijsactiviteiten. Het aantal benodigde trainingen wordt geschat op basis van aanwezigheidsregistraties van de voorafgaande jaren. Studenten kunnen zich aan het begin van elk blok bij het Skillslab inschrijven voor trainingen. Er worden in eerste instantie iets te weinig mogelijkheden aangeboden, zodat alle groepen gevuld worden. Pas daarna worden reservemogelijkheden aangeboden. De inschrijving geschiedt op inschrijfvellen waarop voor elke training in het betreffende blok het tijdstip en de naam van de

Figuur 1. De opkomst bij alle vaardigheidstrainingen in het Skillslab van een cohort van 99 studenten die tussen 1993/1994 en 1997/1998 de eerste vier studiejaren voltooiden. De curves geven voor elk studiejaar per training het percentage weer van de aangeboden trainingsmogelijkheden dat door de studenten is benut.

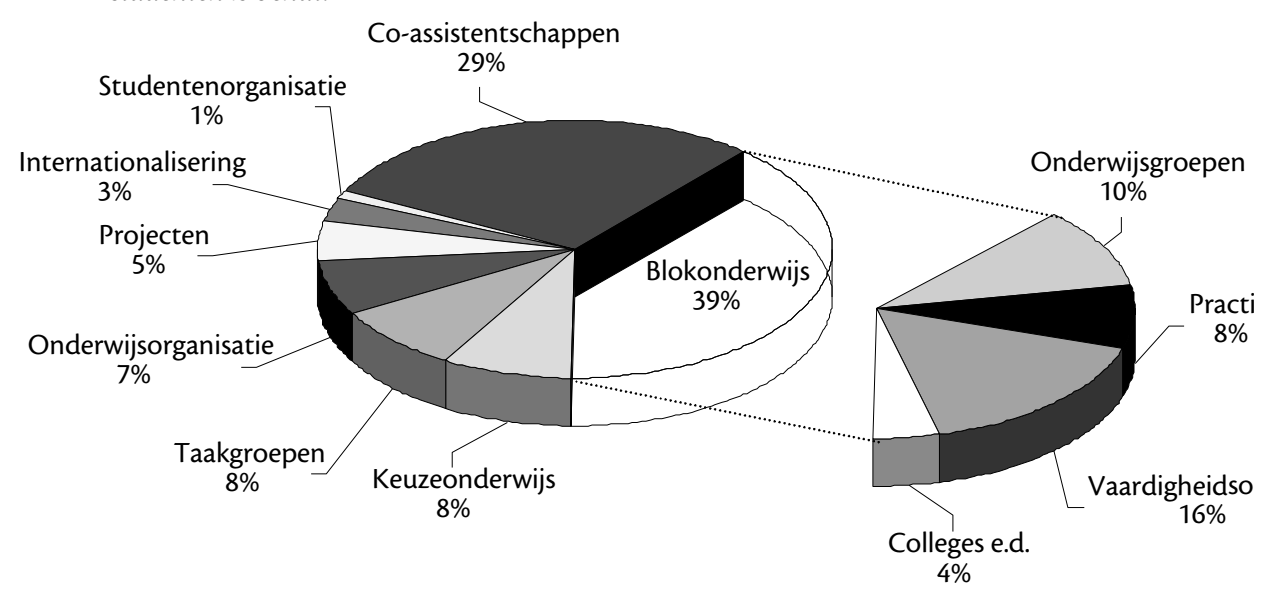


docent staan. Er is dus een beperkte mogelijkheid om voor een specifieke docent van het Skillslab te kiezen. De meeste trainingen worden gegeven in groepen van acht studenten, tenzij het voor de inhoud van de training handig is als de groep kleiner is. Zo wordt bijvoorbeeld het onderzoek van mammae in groepen van zes studenten geoefend. De meeste trainingen duren anderhalf uur. Een vaste tijd is van belang om flexibel te kunnen plannen en tegelijkertijd de ruimtes optimaal te benutten. In de blokboeken wordt de inhoud van de trainingen beschreven en worden voorbereidingsadviezen gegeven. De vaardigheden zijn bovendien uitgebreid beschreven in zogenaamde standaarden. De studenten kunnen zich hiermee voorbereiden op de trainingen en ook zelf oefenen. Veel vaardigheden kunnen de studenten thuis oefenen, maar voor sommige vaardigheden zijn materialen en/of modellen nodig. Op het Skillslab is een aantal kamers beschikbaar om docent-onafhankelijk te oefenen. Studenten kunnen deze kamers reserveren, ook in de avonduren en de weekenden.

Communicatievaardigheden worden geoefend in samenhang met het afnemen van de anamnese en het lichamelijk onderzoek. Deze trainingen worden gegeven in groepen van tien studenten, die het hele jaar dezelfde samenstelling hebben. De studenten schrijven zich aan het begin van het jaar voor deze groepen in. De groepen worden in het eerste en tweede jaar begeleid door één docent en in het derde en vierde jaar door twee docenten (een arts en een gedragswetenschapper). De groepen in het tweede jaar worden begeleid door docenten van het Skillslab; in de andere jaren worden docenten van verschillende vakgroepen ingezet. Voor de patiënten- en praktijkcontacten die in de eerste vier studiejaren buiten het Skillslab worden georganiseerd wordt verwezen naar Schaper et al. 9

\section{Onderzoek naar de effecten van het vaardigheidsonderwijs}

Er zijn de afgelopen jaren verschillende onderzoeken gedaan naar de effecten van het Maastrichtse vaardigheidsonderwijs. De onderzoeksvragen uit deze studies betreffen enerzijds de voorbereiding van studenten op de co-assistentschappen en anderzijds de beheersing van vaardigheden. In interfacultaire studies is onderzoek gedaan bij studenten uit Maastricht en studenten uit de "oude" curricula in Groningen, Nijmegen, Gent en Antwerpen. Wat het effect is van de curriculumherzieningen in deze vier faculteiten is nog niet onderzocht.

\section{Hoe zijn studenten door het vaardigheids- onderwijs voorbereid op de co-assistent- schappen?}

Deze vraag kan zowel door studenten als door docenten worden beantwoord. In onderzoek is de mening van beide groepen gepeild. Docenten gaven zeer uiteenlopende oordelen over de mate van voorbereiding. Ook bleken zij over het algemeen te hoge en niet altijd realistische verwachtingen te hebben van de voorbereiding. ${ }^{1}$ Studenten in Maastricht bleken tevreden te zijn over hun voorbereiding op de co-assistentschappen. ${ }^{10} \mathrm{Het}$ onderzoek hiernaar leverde een aantal goede suggesties op van studenten voor verbeteringen in het vaardigheidsonderwijs. De studenten waren bijvoorbeeld van mening dat er meer patiëntencontacten in de eerste vier jaar georganiseerd moeten worden. ${ }^{1}$ Binnen het bestaande curriculum is dit inmiddels ten dele gerealiseerd. Uit een analyse van de programma-evaluatie van de co-assistentschappen in Maastricht over een periode van vijf jaar bleek dat studenten zich in alle onderzochte jaren, bij alle co-assistentschappen en op alle stageplaatsen (zowel in het academisch ziekenhuis als in de perifere zie- 
kenhuizen) beter voorbereid voelden wat betreft vaardigheden dan wat betreft hun theoretische kennis. ${ }^{11}$ Hoewel het domein van de vaardigheden beperkter is dan dat van de theorie, was met name de consistentie van deze bevinding opmerkelijk. Of dit betekent dat er met de theoretische voorbereiding iets mis is, is niet bekend.

Om de mening van studenten over de voorbereiding te kunnen "ijken", is ook interfacultair onderzoek gedaan. Studenten uit Maastricht bleken zich beter voorbereid te voelen op de co-assistentschappen dan hun collegae uit Groningen en Nijmegen. ${ }^{12}$ Uit dezelfde studie bleek dat de Maastrichtse studenten negatiever oordeelden over de co-assistentschappen dan hun collegae elders. Een verklaring hiervoor zou kunnen zijn dat het contrast tussen de aandacht voor onderwijs in de eerste vier studiejaren (waarover de Maastrichtse studenten immers tevreden zijn) en het gebrek daaraan in de co-assistentschappen in Maastricht wellicht groter is dan aan de andere faculteiten. Om hier meer inzicht in te krijgen, is in een volgende studie een enquête opgesteld op basis van de vaardighedenlijst uit het Raamplan 1994 Artsopleiding en voorgelegd aan co-assistenten uit Groningen en Maastricht. Er waren vakgebieden waarop de Groningers beter waren voorbereid (zoals psychiatrie en neurologie). Er waren echter meer vakgebieden waarop de Maastrichtse studenten zich beter voorbereid voelden dan hun Groningse collegae. ${ }^{13}$ De gevonden verschillen konden verklaard worden uit verschillen tussen de curricula en dat maakt de bevindingen "steviger". Een onverwachte bevinding was dat de Maastrichtse co-assistenten tijdens hun co-assistentschap niet alleen vaker maar ook meer vaardigheden uitvoerden dan de Groningse co-assistenten. Een goed voorbereide student lijkt de geboden gelegenheden beter te benutten tijdens de co-assistentschappen. Onlangs is gevonden dat Maastrichtse co-assistenten ook meer vaardigheden vaker uitvoeren dan hun collegae uit Antwerpen. ${ }^{14} \mathrm{De}$ bevindingen in deze verschillende studies zijn consistent, hetgeen een sterke aanwijzing vormt dat de gevonden verschillen echte verschillen zijn, ook al zijn de bevindingen gebaseerd op de meningen van studenten. Dat neemt niet weg dat ook onderzoek naar de feitelijke beheersing van vaardigheden van belang is.

\section{Hoe beheersen studenten de vaardigheden?}

Er werd in 1995 een stationsexamen georganiseerd voor vierde- en zesdejaars studenten uit Groningen en Maastricht. De inhoud van de stations was afgestemd op het vaardigheidsonderwijs in Groningen, omdat dit minder uitgebreid is dan in Maastricht. De Groningse vierdejaars studenten hadden vlak voor het stationsexamen een cursus van twaalf weken gevolgd, waarin zij de vaardigheden die getoetst werden, geleerd hadden. Bij de vierdejaars studenten werd geen verschil gevonden tussen beide faculteiten, hetgeen mogelijk verklaard kan worden door de beperkte inhoud van de toets. De zesdejaars studenten uit Maastricht scoorden significant beter dan hun Groningse collegae. Bij de Groningse studenten werden tussen de scores in het vierde en het zesde jaar geen verschillen gevonden. In Maastricht scoorden de zesdejaars studenten echter wel beter dan de vierdejaars studenten. ${ }^{1}$ Dat de beheersing van vaardigheden van Maastrichtse studenten tijdens de co-assistentschappen verbetert, past bij de eerder beschreven bevinding dat Maastrichtse studenten meer vaardigheden vaker uitvoeren. Een andere verklaring kan zijn dat de Maastrichtse studenten in hun zesde jaar nog een stationsexamen moeten afleggen, waardoor zij bewust vaardigheden blijven oefenen. 
Naast het stationsexamen werd aan dezelfde studenten een kennis-over-vaardighedentoets voorgelegd. Deze toets bevatte vragen over een breder domein dan het stationsexamen. De vierdejaars studenten uit Maastricht scoorden beter dan de Groningse studenten, namelijk even hoog als de zesdejaars uit Groningen. In het zesde jaar was er geen verschil. In Groningen verbeterde de kennis over vaardigheden tussen het vierde en het zesde jaar. In Maastricht was dat niet het geval. Waarschijnlijk is er sprake van een plafondeffect, dat samenhangt met de moeilijkheidsgraad van de toets. In deze studie werd ook gevonden dat met een schriftelijke toets een goede voorspelling gedaan kan worden, voor groepen (niet voor individuele) studenten, over prestaties op een stationsexamen. In een volgende studie is op basis hiervan alleen een kennis-over-vaardighedentoets voorgelegd aan eerste- tot en met zesdejaars studenten in Groningen en Maastricht. In het tweede tot en met het zesde jaar was er een significant verschil in het voordeel van Maastricht (figuur 2). 15

Inmiddels hebben ook studenten uit de laatste vier studiejaren in Gent en Antwerpen een deel van deze toets gemaakt. De Maastrichtse studenten scoorden significant hoger op deze subtoets dan de collegae uit Groningen, Gent en Antwerpen. ${ }^{14}$

\section{Toekomstbeeld}

Concluderend, lijken de resultaten van het onderzoek naar de effecten van het vaardigheidsonderwijs overwegend positief voor Maastricht. Toch moeten wij, als docenten, onszelf voortdurend de vraag blijven stellen: hoe kunnen we ons onderwijs verbeteren? De suggestie van studenten om meer patiëntencontacten in de eerste vier studiejaren te organiseren biedt hiervoor een goed aanknopingspunt. Een extra argument voor verbetering is dat er inmiddels aanwijzingen zijn dat de studenten moeite hebben met de overgang

Figuur 2. Gemiddelde scores (percentage goed-fout) op een kennis-over-vaardighedentoets van studenten uit de jaargroepen 1 tot en met 6 in Groningen (oude curriculum) en Maastricht. 
naar de co-assistentschappen. ${ }^{16,17} \mathrm{Om}$ gedachten te ontwikkelen over verbeteringen in het leren oplossen van (patiënten)problemen is het van belang om in te gaan op inzichten hierover uit de cognitieve psychologie. Een aantal jaren geleden werd probleemoplossen beschouwd als een geïsoleerde vaardigheid, die als zodanig geoefend kan worden. Uit cognitief psychologisch onderzoek is gebleken dat deze opvatting niet klopt. Vaardig probleemoplossen blijkt in hoge mate afhankelijk te zijn van de inhoud van het probleem. ${ }^{18-20}$ Ook is ontdekt dat er verschillen zijn wat betreft probleemoplossen tussen experts en beginners. Experts kunnen verworven kennis beter toepassen dan beginners, doordat zij in hun geheugen "kennisnetwerken" hebben ontwikkeld die goed toegankelijk zijn. ${ }^{18-20}$ Daardoor is de kennis van experts direct beschikbaar op het moment dat deze toegepast moet worden. Beginners moeten hun kennisnetwerk nog ontwikkelen. Voor het onderwijs betekent dit dat nieuwe informatie een goede plaats in het "netwerk-in-ontwikkeling" moet krijgen. Vanuit dit perspectief is probleemgestuurd onderwijs in een kleine groep een geschikte onderwijsvorm. Als het echter in de praktijk van het onderwijs- en toetssysteem toch meer om geïsoleerde feiten en vaardigheden gaat, worden er geen goede netwerken aangelegd. De informatie wordt dan niet goed opgeslagen en zal in de praktijk vaak niet teruggevonden kunnen worden. Samengevat: onderwijs dat de nadruk legt op geïsoleerde (feiten)kennis en vaardigheden leidt alleen tot een kortetermijnleereffect en goede resultaten op de betreffende toetsen. Ook is inmiddels bekend dat er geoefend moet worden met de "oude" informatie in de netwerken. ${ }^{18-20}$ De redenen hiervoor zijn dat door oefenen de informatie beter beklijft, de netwerken beter gaan functioneren en - als er goede begeleiding is - misconcepties duidelijk worden. Omdat het opslaan en terugzoeken van informatie contextgebonden blijkt te zijn, moet er geoefend worden in verschillende situaties, die geleidelijk meer overeenkomen met de werkelijke situatie waarin de student het probleem moet kunnen oplossen. De context waarin studenten geneeskunde een probleem moeten kunnen oplossen is het arts-patiëntcontact. Bij de opbouw van het curriculum zou dus het arts-patiëntcontact de rode draad moeten zijn. Aan het begin van het curriculum moeten er onderwijssituaties gecreëerd worden die lijken op een arts-patiëntcontact en aan het einde van het curriculum functioneert de student als arts. Tussen het begin en het einde komt de student in aanraking met praktijk- en patiëntenproblemen, die geleidelijk "echter" en ingewikkelder worden. Aan het einde van het curriculum moet de student uiteraard beschikken over goed functionerende kennisnetwerken. Dat betekent dat arts-patiëntcontacten met voldoende diepgang moeten worden nabesproken, met aandacht voor pathofysiologie, en in een klimaat waarin misconcepties aan het licht kunnen komen. Het realiseren van deze gedachten vergt een heel andere curriculumopbouw dan de algemeen gebruikelijke. De meeste curricula lijken op een (gekantelde) $\mathrm{H}$, met een strikte scheiding tussen de eerste vier studiejaren en de laatste twee studiejaren. In de eerste vier jaar vinden relatief weinig patiëntencontacten plaats en de laatste twee jaar bestaan vrijwel volledig uit praktijkcontacten.

Bij de curriculumherzieningen van de afgelopen jaren in Amsterdam, Groningen en Nijmegen is er al veel ten goede veranderd in de eerste vier studiejaren. Er wordt meer in kleine groepen gewerkt aan taken of het oplossen van problemen, het vaardigheidsonderwijs wordt meer verspreid 
over het curriculum gegeven, et cetera. ${ }^{21}$ In de laatste twee jaar, de co-assistentschappen, verblijft de student een (historisch bepaald) aantal weken op een afdeling. Er is al langere tijd kritiek op deze fase van de opleiding, die als volgt samengevat kan worden. Studenten zien gemiddeld weinig patiënten en er is een grote spreiding tussen individuele studenten; studenten worden zelden of nooit geobserveerd tijdens anamnese en onderzoek; de praktijkcontacten vinden voornamelijk plaats op klinische afdelingen, terwijl de voor onderwijs interessante patiëntenzorg zich steeds meer verplaatst heeft naar de polikliniek en extramuraal.22-25 Een aantal faculteiten heeft de afgelopen jaren plannen gemaakt om de co-assistentschappen te herzien. Een herkenbare grote lijn in deze herzieningen is dat er een betere opbouw - van werken onder strikte supervisie naar eigen verantwoordelijkheid - wordt nagestreefd en dat er meer aandacht aan het leren van de student wordt besteed. 26,27

We lijken in het Nederlandse medisch onderwijs dus onmiskenbaar op de goede weg. Als we in de toekomst de inzichten uit de cognitieve psychologie nog beter kunnen en willen vertalen naar de onderwijspraktijk, moeten we gaan werken aan een zesjarig Z-vormig curriculum ter vervanging van het (gekantelde) $\mathrm{H}$-vormige model, dat in feite uit vier jaar theorie en twee jaar praktijk bestaat. In een Z-vormig curriculum beginnen patiënten- en praktijkcontacten vroeger in het curriculum en wordt in de laatste jaren dieper op de theorie ingegaan dan tot nu toe gebruikelijk is. De plannen van de Utrechtse collegae lijken op dit moment het meest op het hier beschreven toekomstbeeld. ${ }^{28}$ In Maastricht is inmiddels ook gekozen voor een Z-vormig curriculum. 29

\section{Consequenties voor het vaardigheids- onderwijs}

Het beschreven toekomstbeeld heeft uiteraard consequenties voor het vaardigheidsonderwijs. Het verwerven en verdiepen van kennis, het aanleren van vaardigheden en het reflecteren over attitude zijn onlosmakelijk met elkaar verbonden in de context van patiënt en praktijk. Betekenen vroege patiëntencontacten dat we teruggaan naar het verleden, toen studenten, onvoorbereid en alleen, patiënten in het ziekenhuis onderzochten? Het antwoord is nee. Studenten moeten zich goed kunnen voorbereiden. Dat zijn wij, als docenten, aan hen en aan de patiënten verplicht. Goede voorbereiding is niet in tegenspraak met leren in de context. Er is niets op tegen om als voorbereiding een patiëntenprobleem op papier op te lossen of lichamelijk onderzoek op elkaar te oefenen. Het gaat erom dat de tijdspanne tussen de voorbereiding "op papier" of "op elkaar" en de "echte patiënt" of de "echte praktijk" niet zo lang moet zijn als nu vaak het geval is. Het gaat om het vinden van de goede balans tussen theorie en praktijk, tussen "echt" en "simulatie". Voor het (vaardigheids)onderwijs moeten we dus creatief nadenken over een nieuw zesjarig curriculum. Daarbij moet ervoor gezorgd worden dat het vaardigheidsonderwijs goed geïntegreerd aangeboden wordt in een nieuw curriculum en dat er geen "eigen" rode draad ontstaat, die er achteraf ingeweven wordt. Er zijn inmiddels al veel goede initiatieven die passen bij de toekomstige ontwikkeling. Zo wordt bijvoorbeeld in het Skillslab in Maastricht het neurologisch onderzoek geoefend met patiënten van patiëntenverenigingen. De studenten oefenen zo vaardigheden in de context, zien en voelen afwijkingen en ontdekken dat afwijkingen opgespoord kunnen worden met eenvoudige diagnostiek. Een ander voorbeeld is dat in con- 
tacten met simulatiepatiënten het oefenen met het oplossen van het probleem de laatste jaren belangrijker is geworden.

\section{Ten slotte}

De veranderingen in het medisch onderwijs gaan de afgelopen jaren heel snel. De grote lijn in deze veranderingen is dat het "studerend leren" en het "leren studeren" van de student meer centraal is komen te staan. Wij lijken op de goede weg. Een nieuwe ontwikkeling is dat de patiënt centraal zou moeten staan.

Er zijn weliswaar steeds meer wetenschappelijk gefundeerde inzichten die de onderwijsontwikkelingen ondersteunen, maar er is ook nog veel dat we niet weten. Dat betekent dat we als docenten kritisch moeten blijven door samen met studenten steeds te onderzoeken of we nog op de goede weg zitten.

\section{Literatuur}

1. Scherpbier AJJA. Kwaliteit van vaardigheidsonderwijs gemeten [proefschrift]. Maastricht: Universitaire Pers; 1997.

2. Scherpbier AJJA. Bartholomeus PMTA. Vaardigheidsonderwijs in het Skillslab. Voldoet het programma aan de criteria van studeerbaarheid? Bulletin Medisch Onderwijs 1996;15(1):28-36.

3. Schaper NC, Scherpbier AJJA, Snellen-Balendong H. Hoe doelen van het vaardigheidsonderwijs vast te stellen voor de eerste vier jaren van de medische opleiding in Maastricht? In: Pols J, Cate ThJ ten, Houtkoop E, Pollemans MC, Smal JA, redactie. Gezond Onderwijs-4. Houten/Zaventem: Bohn Stafleu Van Loghum; 1995. p. 216-20.

4. Vleuten CPM van der, Verwijnen GM, Wijnen WHFW. Fifteen years of experience with progress testing in a problem based learning curriculum. Med Teach 1996;18(2):103-9.

5. Luijk SJ van. Al doende leert men [proefschrift]. Maastricht: Rijksuniversiteit Limburg; 1994.

6. Vleuten CPM van der. Naar een rationeel systeem voor toetsing van studieprestaties in probleemgestuurd medisch onderwijs: studies naar betrouwbaarheid en validiteit van toetsen voor praktische vaardigheden [proefschrift]. Amsterdam: Thesis; 1989.

7. Scherpbier AJJA, Kerkhofs E, Verhoeven BH, Gerwen ALEM van, Wolfhagen HAP, Vleuten CPM van der. Trends in de aanwezigheid bij het vaardigheidsonderwijs. Bulletin Medisch Onderwijs 1998;17(4):143-8.

8. Bokhoven MA van, Verhoeven BH, Scherpbier AJJA, Kerkhofs E, Gerwen ALEM van, Luyk SJ van, Vleuten CPM van der. De relatie tussen aanwezigheid tijdens vaardigheidstrainingen en studieresultaten: een cohortstudie. Bulletin Medisch Onderwijs 1999;18(2):66-73.

9. Schaper NC, Scherpbier AJJA, Crebolder H, Arends JW. Praktijkonderwijs in de eerste vier jaren van de medische opleiding in Maastricht. In: Pols J, Cate ThJ ten, Houtkoop E, Pollemans MC, Smal JA, redactie. Gezond Onderwijs-4. Houten/ Zaventem: Bohn Stafleu Van Loghum; 1995. p. 221-6.

10. Louw A de, Weg $\mathrm{N}$ van de, Webers J, Scherpbier AJJA, Schaper N. Wat vinden co-assistenten van de voorbereiding in het Skillslab op de co-assistentschappen? In: Houtkoop E, Pols J, Pollemans MC, Scherpbier AJJA, Verwijnen GM, redactie. Gezond Onderwijs-3. 's-Gravenhage: Haagse Hogeschool; 1994. p. 119-24.

11. Scherpbier AJJA, Wolfhagen HAP, Essed GGM. Het oordeel van co-assistenten over de voorbereiding op de co-assistentschappen in Maastricht. Bulletin Medisch Onderwijs 1994;13(4):178-83.

12. Scherpbier AJJA, Busari JO, Boshuizen HPA, Hiemstra RJ, Metz JCM. Hoe voelen studenten zich voorbereid op de praktijk? Een vergelijking tussen drie faculteiten geneeskunde. Bulletin Medisch Onderwijs 1996;15(1):17-22.

13. Scherpbier AJJA, Louw A de, Verrijn Stuart AA, Keuning FM, Pols J. Vaardigheden in de praktijk: een vergelijking tussen Groningen en Maastricht. In: Cate ThJ ten, Dikkers JH, Houtkoop E, Pollemans MC, Pols J, Smal JA, redactie. Gezond Onderwijs-5. Houten/Diegem: Bohn Stafleu Van Loghum; 1996. p. 359-66.

14. Remmen R. Evaluatie van het vaardigheidsonderwijs aan geneeskunde studenten van de Universiteit van Antwerpen [proefschrift]. Antwerpen: Universiteit Antwerpen; 1999.

15. Scherpbier AJJA, Verhoeven BH, Bloemen JCM, Cohen-Schotanus J, Pols J, Rossum HJM van, et al. De toename van beheersing van vaardigheden gedurende het curriculum. Een vergelijking tussen Groningen en Maastricht. Bulletin Medisch Onderwijs 1997;16(2):101-7.

16. Wiel MWJ van de, Schaper NC, Scherpbier AJJA, Vleuten CPM van der, Boshuizen HPA. Students' experiences with real patients tutorials in a problem-based curriculum. Teaching and Learning in Medicine 1999;11(1):12-20.

17. Prince CJAH, Wiel MWJ van de, Scherpbier AJJA, Vleuten CPM van der, Boshuizen HPA. De overgang van theorie naar praktijk in het medisch curriculum. Tijdschrift voor Medisch Onderwijs. Ter perse 2000 . 
18. Regehr G, Norman GR. Issues in cognitive psychology: implications for professional education. Acad Med 1996;71(9):988-1001.

19. Schmidt HG, Norman GR, Boshuizen HPA. A cognitive perspective on medical expertise: theory and implications. Acad Med 1990;65(10):611-21.

20. Boshuizen HPA. De ontwikkeling van medische expertise; implicaties voor het praktisch en theoretisch medisch onderwijs. In: Metz JCM, Scherpbier AJJA, Vleuten CPM van der, redactie. Medisch onderwijs in de praktijk. Assen: Van Gorcum; 1995. p. 25-39.

21. VSNU-Visitatiecommissie Geneeskunde en Gezondheidswetenschappen. Onderwijsvisitatie geneeskunde en gezondheidswetenschappen. Utrecht: Vereniging van Samenwerkende Nederlandse Universiteiten; 1997.

22. Scherpbier AJJA, Metz JCM. Co-assistentschap: een stage? Bulletin Medisch Onderwijs 1989;8 (2):64-7.

23. Weg $N$ van de, Visser $K$, Seuren $M$, Scherpbier AJJA, Wolfenbuttel BHR, Wolfhagen HAP. Tijdsbesteding van co-assistenten nader bekeken. Bulletin Medisch Onderwijs 1993;12(4):173-9.

24. Szenas P. The role of faculty observation in assessing students' clinical skills. Contemporary Issues in Medical Education 1997;1(1):1-2.

25. Pols J, Scherpbier AJJA. Welke patiënt ziet de coassistent: waarom ziekenhuisafdelingen steeds minder geschikt zijn voor de opleiding tot basisarts. In: Vleuten CPM van der, Scherpbier AJJA, Pollemans M, redactie. Gezond Onderwijs-1. Houten: Bohn Stafleu Van Loghum; 1992. p. 174-6.

26. Cate ThJ ten, Danner SA, Lanschot J van, Büller HA, Michels RP, Krol LJ, et al. Herziening co- assistentschappen AMC: hoofdlijnen van een nieuwe vormgeving. In: Verweij AMJJ, Albersnagel EA, Cate ThJ ten, Denekens J, Dikkers JH, Remmen R, et al., redactie. Gezond Onderwijs-7. Houten/ Diegem: Bohn Stafleu Van Loghum, 1998; p. 75-8.

27. Bestuurscommissie Herziening Curricula. Vernieuwing co-assistentschappen. Nijmegen: Faculteit der Medische Wetenschappen; 1997.

28. Blauwdruk I nieuw curriculum Utrecht. Utrecht: Opleidingsbestuur; 1998.

29. Scherpbier AJJA, Crebolder H, Essed G, Santen M van, Schaper N, Schrander J, et al. Van papier naar patiënt; gedachten over curriculumverbetering. Interne notitie aan Bestuur Faculteit der Geneeskunde. Maastricht: Universiteit Maastricht; april 1998.

De auteurs

Dr. AJJA Scherpbier, wetenschappelijk directeur van het Onderwijsinstitut. G.M. Verwinen, hoofa van het skinslab.

Dr. N. Schaper, internist, coordinator Fraktisch Medisch Onderwij jaar $1-4$.

Dr. G.A.J. Dunselman, gynacoloog, portefeuilehouder onderwis van het Bestuir.

Frof. dr. C.P.M. wan der Vleuten, woorzitter capaciteitsgroep onderwijsontwikkeling en Onderwijsesearch. Allen zin werbonden adn de Faculteit der Geneeskunde wan de Universiteit Maastricht.

Correspondentieadres:

Dr. A.J.A. Scherpbier, Onderwijsinstituut, Faculteit der Geneskunde, Fostbus 616, 6200 MD Mastricht, email: a.scherpbier@oifg.unimaas.nt. 